\title{
Team Learning from Mistakes: The Contribution of Cooperative Goals and Problem-Solving*
}

\section{Dean Tjosvold, Zi-you Yu and Chun Hui}

Lingnan University, Hong Kong; Lingnan University, Hong Kong; The Chinese University of Hong Kong

ABSTRACT Although mistakes may have considerable potential for learning, previous research has emphasized that organizational members are often defensive when their mistakes are pointed out and will even continue with their present course of action despite growing costs. Recent research has shown that team-level variables, such as psychological safety and shared mental model, can help overcome barriers to learning from mistakes. Structural equation analyses on teams working in a sample of organizations in Shanghai, China, suggested that teams were able to learn from their mistakes to the extent that they took a problem solving orientation. This orientation in turn was based on developing cooperative but not competitive goals within the team. Although competitive and independent goals induce blaming, blaming itself was not significantly related to learning. Blaming, especially when conducted openly, may hold individual team members accountable as well as provoke defensiveness. Findings empirically link the theory of cooperation and competition with the organizational learning literature. Results suggest that cooperative goals and problem solving promote learning from mistakes.

\section{INTRODUGTION}

Learning from experience is recognized as vital in order for organizations to respond to rapid changes in technology and market forces (Levitt and March, 1988; Luo and Peng, 1999). Since organizations increasingly rely upon teams to make important decisions, research is needed to understand how organizational teams can learn from mistakes and avoid costly misjudgements (Adler and Kwon, 2002; Buffardi et al., 2000; Druskat and Kayes, 2000; Ely and Thomas, 2001; Zohar, 2000). Yet learning from mistakes is challenging and not well understood, especially in team contexts (Edmondson, 1999). Considerable research suggests

Address for reprints: Dean Tjosvold, Lingnan University, Hong Kong (tjosvold@ln.edu.hk). 
that individuals and teams are tempted to defend and continue their present course of action despite clear evidence that this action is misguided (Bazerman, 1997; Staw, 1981). Interaction between organizational members has been theorized to impact learning substantially, although not necessarily in a positive way (Arygris and Schon, 1978, 1996; Fisher and White, 2000; Jazabkowski and Wilson, 2002; Kraatz, 1998; Lane and Lubatkin, 1998; Nonaka and Takeuchi, 1995; Senge, 1990; Simonin, 1997). The present study focuses on the interaction and goal interdependence among team members in order to understand how teams learn from their mistakes. We argue that interaction in terms of a problem solving or a blaming approach, and interdependence in terms of the kind of goals team members perceive themselves to hold towards each other, very much affects the extent to which organizational teams are able to learn from errors. Specifically, we test the hypotheses that cooperative goals within groups facilitate team problem solving and learning from mistakes, whereas competitive and independent goals promote blaming, which undermines learning.

\section{The Challenge of Learning from Mistakes}

Considered critical for helping organizations create innovative solutions and compete successfully in the changing marketplace (Levitt and March, 1988; Luo and Peng, 1999), learning involves understanding new ideas and incorporating them into one's own thinking (Crossan et al., 1999). Research has confirmed that learning can contribute substantially to organizational performance (Luo and Peng, 1999; VandeWalle et al., 1999). Experiential learning is thought to be a particularly useful and effective way for organizations and their members to learn from mistakes (Carter and West, 1998; West, 1996). Team members reflect on their performance and its consequences, discover cause and effect relationships, and identify weaknesses and strengths in their own efforts. They gain insight into their own behaviour, develop and implement changes, and prepare for future challenges.

While learning can take place when one acquires knowledge that one previously did not possess, an important source of learning is from mistakes and errors. As long as organization attempt to make changes, mistakes and errors are likely to occur. Mistakes and errors, though almost inevitable and often times costly, can also provide valuable experience from which to learn (Akbar, 2003; Nonaka and Takeuchi, 1995; Starkey, 1998). Learning from mistakes involves recognizing that unexpected, undesired effects have occurred and reflecting on these experiences to reduce the probability of their future occurrence (Cannon and Edmondson, 2001). Reflecting on mistakes may reveal insights that correct misunderstandings of the situation and identification of shortcomings that frustrate effective action (Edmondson, 1996, 1999; West, 1996).

But how can this important outcome of learning from mistakes be fostered? Theorists have proposed that collaboration and interaction among individuals, 
groups, and organizations are the bases for experiential learning (Fisher and White, 2000; Lane and Lubatkin, 1998; Nonaka and Takeuchi, 1995; Senge, 1990). International partners can learn from each other to strengthen their alliances especially in rapidly changing marketplaces (Luo and Peng, 1999). Interaction among organizational members appears to be critical for their ability to reflect on their experiences and learn from mistakes (Kale et al., 2000). However, interaction itself is unlikely to facilitate learning uniformly. Interaction can reinforce biases and defensiveness rather than openness and learning (Houghton et al., 2000; Schwenk, 1984; Van Knippenberg et al., 2000). Organizational members may join together to make excuses for their behaviour and reinforce their closed-mindedness. They can blame mistakes on other members and believe that they have little to learn, convinced that others should change their ways. Thus, in order to understand how to foster learning from mistakes, it is important to investigate the nature of interaction among those who are to benefit from these mistakes.

\section{Contribution of the Present Study}

Many organizations are relying upon teams to help them manage rapid changes and uncertainty. The present study builds upon recent research that examined the value and conditions when teams learn (Adler and Kwon, 2002; Cannon and Edmondson, 2001; Druskat and Kayes, 2000; Edmondson, 1996, 1999; Ely and Thomas, 2001; Zohar, 2000). It also builds upon growing research that developed the insight that interaction critically affects organizational learning. For example, Edmondson $(1996,1999)$ proposed that leader behaviours and team psychological safety are vital to learning from mistakes; Cannon and Edmondson (2001) suggested that having shared mental models would enhance learning from mistakes; Argyris and Schon (1978) argued that theories-in-use may explain the lack of openness to learning from mistakes.

The present study examines how team members can learn from mistakes by focusing on the various approaches to learning and the kind of interaction that fosters or impedes these approaches. Team members can engage in open problem solving, where together they discuss errors to understand and make improvements, but they can also be blame-oriented and unwilling to learn. Open problem solving is an approach to learning that is more likely to generate positive team outcomes, including learning from mistakes, than the approach characterized by a blameorientation. An important question then must be: 'what induces problem solving and blame-oriented interaction?'.

This study proposes that the nature of the interdependence among team members in terms of how they perceive their goals to be related to each other's goals very much affects team problem solving and learning from mistakes. It suggests that developing cooperative relationships among team members leads them to a problem solving approach and helps them learn from mistakes. Competitive 
and independent goals, however, induce blaming and little learning. This study empirically links the theory of cooperation and competition and its considerable experimental research support (Johnson and Johnson, 1989; Johnson et al., 1981; Stanne et al., 1999) with the literature on organizational and team learning.

\section{Blaming Approach}

Teams are unlikely to learn effectively from their mistakes if their interaction is focused on blaming others. Arygris and Schon (1978, 1996) concluded that people in organizations typically interact in ways that block learning. They labelled this way of interacting as the Model I approach to problem solving. Arygris and Schon suggested that managers tend to adopt values and subsequent actions to avoid emotionally laden discussions, exercise unilateral control, and win interpersonal conflicts. The emphasis is on blaming others and trying to make oneself look competent at the expense of others (Alicke, 2000). Organizational members are more interested in winning and protecting their reputation than in self-examination and development. These values result in closed-mindedness and a rigid commitment to current practices.

This kind of blaming may impede team members' learning from mistakes. In this approach, team members punish and embarrass others as responsible for errors as they try to avoid being held responsible themselves (Arygris and Schon, 1978, 1996). Fearing punishment and embarrassment, they try to hide errors and to cover up mistakes that might be attributed to them and seek to have mistakes attributed to others. Research suggests that blaming makes discussions more threatening and divisive (Rybowiak et al., 1998; Van Dyck et al., 1998). These dynamics seem unlikely to result in much team learning from mistakes (De Dreu and Van de Vliert, 1997; Dweck and Leggett, 1988; Eliott and Dweck, 1988; Folger and Skarlicki, 1998; Kelman, 1997; Rubin et al., 1994; Pruitt and Syna, 1989).

Other research also indicates that mistakes often generate defensiveness to learning. Studies, for example, have shown that organizational members are willing to commit to additional resources, despite abundant evidence that their present course of action is costly (Bazerman, 1997; Staw, 1981). Edmonson (1996, 1999) has found powerful, pervasive psychological and organizational barriers that impede the behaviours through which learning from mistakes can occur.

Based on the above research and reasoning, it is hypothesized that:

Hypothesis 1: A blaming approach reduces group learning from mistakes.

\section{Problem Solving Approach}

In contrast to blaming, taking a problem solving approach appears to help teams learn from mistakes (Cannon and Edmondson, 2001; Carter and West, 1998; 
Edmondson, 1999). Problem solving involves the open discussion among group members of their error, in order to understand the conditions that led to it. This understanding allows members to improve future performance. Team members honestly examine the incident of undesired effects and develop a comprehensive analysis of the contributors to the error. They share their experience and delve into how they can correct the error and reduce the probability of its recurrence, even though that means admitting their mistakes.

Although they believe interaction typically impedes learning, Arygris and Schon (1978, 1996) have identified a Model II approach to problem solving that promotes a thorough reflection of mistakes and issues and an openness to learning. The values of openness, joint responsibility, and mutual influence, when genuinely applied, facilitate the communication and acceptance of information and feedback even about mistakes. This communication in turn results in learning. With these values, the emphasis is on understanding the problem fully and developing quality solutions.

Evidence supports the proposition that a problem solving approach to dealing with issues and mistakes can foster learning, whereas blaming makes discussions more threatening and divisive (Rybowiak et al., 1998; Van Dyck et al., 1998). Problem solving appears to contribute to resolving a range of organizational issues and conflicts (De Dreu and Van de Vliert, 1997; Folger and Skarlicki, 1998; Kelman, 1997; Pruitt and Syna, 1989; Rubin et al., 1994). Taking a developmental, problem solving perspective, rather than a judgmental one can help individuals learn from their experience and improve their organizational performance (Dweck and Leggett, 1988; Eliott and Dweck, 1988; VandeWalle et al., 1999). Problem solving appears quite useful for helping teams learn from mistakes.

Evidence for the importance of a problem solving approach to learning is also available from studies on leadership and team dynamics. Edmondson (1996) found that health care groups where members felt the psychological safety to discuss medication errors openly were able to identify causes of errors and develop viable innovations to reduce their recurrence. Leaders who provided skilful coaching and direction setting and promoted quality relationships helped employees develop the processes and stability to identify errors (Edmondson, 1999). Specific transformational leadership can help develop safety climates and awareness that reduce dangerous mistakes (Barling et al., 2002). In addition to supporting the value of leader coaching, Cannon and Edmondson (2001) found that shared agreement among team members on using mistakes to learn was an important antecedent to group performance. Developing a shared understanding of the value of safety appears to reduce costly accidents (Zohar, 2000).

Based on the above reasoning, it is hypothesized that:

Hypothesis 2: A problem solving approach promotes group learning from mistakes. 
Taken together, there is evidence that team-level variables such as team climate, leadership, and values are critical for developing a problem solving approach and learning from mistakes. Developing effective relationships among team members may be key to their useful reflection on mistakes and learning from them. However, research is needed to clarify the nature of the interdependence and relationships among group members that impact team problem solving and learning. This study proposes that how group members believe their goals to be related to each other affects their proclivity to interact in a problem solving or blaming mode, thereby affecting their learning from mistakes.

\section{Theory of Cooperation and Competition}

The present study contributes to the research on team learning from mistakes by using the theory of cooperation and competition. It specifies the nature of team relationships that promote a functional problem solving approach to learning from mistakes. Cooperative goals within groups may be a foundation for team problem solving and learning from mistakes.

Researchers have analysed groups in terms of interdependence with such measures as the extent to which team members depend upon each other for completing tasks and how they distribute outcomes (Hackman, 1987; Van Der Vegt et al., 2000; Wageman, 1995; Wageman and Baker, 1997). The theory of cooperation and competition specifies interdependence in terms of how group members believe their goals to be related to each other. The theory proposes that group members may develop contrasting kinds of interdependence, in that they reach different conclusions about how their goals are structured (Deutsch, 1949, 1973). It hypothesizes that the way goals are perceived to be structured determines how team members interact. Whether team members perceive their goals to be related cooperatively or competitively critically affects their expectations, interaction, and outcomes.

Cooperative Goals. According to Deutsch, cooperation occurs when individuals believe that their goal achievements are positively correlated, in that they can reach their goals as others also reach their goals. They conclude that as one person moves toward goal attainment, others move toward reaching their goals. They understand that others' goal attainment helps them; they can be successful together.

With cooperative goals, people want each other to perform effectively, for such competence helps each person be successful. They interact in ways that promote common goals and they resolve issues for mutual benefit.

Competitive Goals. In competition, group members perceive that their goal achievements are negatively correlated; when one person achieves his or her goal, others 
fail to achieve their goals. They may, for example, compete over who is considered the most important member, who should receive the most rewards, or whose ideas should dominate.

People in competition, believing that one's successful goal attainment makes others less likely to reach their goals, conclude that they are better off when others act ineffectively. When others are productive, they are less likely to succeed themselves. They pursue their interests at the expense of others. They want to 'win' and have the other 'lose'. As they work to achieve their own interests, they may be tempted to obstruct the goals of other members.

Learning. Considerable experimental research demonstrates that how people believe their goals are related greatly impacts the dynamics and outcomes of their interaction (Johnson and Johnson, 1989; Tjosvold, 1998). With cooperative goals, team members share information, explain their ideas, support each other's achievements, and challenge each other's thinking. Meta-analyses have documented that overall cooperative compared to competitive goals promote learning, especially in learning complex ideas (Johnson and Johnson, 1989; Johnson et al., 1981; Stanne et al., 1999).

This research suggests that cooperative goals underline a team's proclivity to approach mistakes in a problem solving manner. Cooperatively oriented group members want to promote each other's success and effectiveness so that they can all achieve their goals. Their focus is developing their joint abilities in order to succeed as a team. With this orientation, errors and mistakes are considered impediments to their joint progress toward their goals. As a consequence, they want to fully identify the barriers to their success and develop solutions to overcome them. In this way, they use their mistakes to improve their overall performance.

Based on the above research, it is hypothesized that:

Hypothesis 3: Cooperative goals facilitate group problem solving.

On the other hand, competitively oriented team members want to avoid appearing to have lost. Signs that they have made a mistake are threatening, for they pose the potential of being exposed and losing. Consequently, they work to cover up any mistakes so that they do not appear to be 'losers'. If possible, these group members want to win and show that they are worthier than others. They attribute errors to others to avoid appearing to have lost and to make it more likely that they will appear to be better than others. Competitive goals are expected to increase the temptation to blame mistakes on other group members.

Based on the above research and reasoning, it is hypothesized that:

Hypothesis 4: Competitive goals induce blaming within groups. 
Independent Goals. Much less research has clarified the role of independence when persons believe their goals to be unrelated, so that the success or failure of another has no impact on the goal achievement of others. However, in general, independence goals appear to have effects similar to those of competition (Johnson et al., 1981).

Based on the above research and reasoning, it is hypothesized that:

Hypothesis 5: Independent goals induce blaming within groups.

\section{Studying Interdependence and Learning in China}

This study tests the hypotheses in teams in a variety of organizations in Shanghai, China, where, because of the need to respond to rapid changes in the marketplace, mistakes can easily be made. Although research has focused on differences between the West and the East, it is useful to test the generalizability of the theory of cooperation and competition developed in the West for understanding group dynamics in China (Hofstede, 1993). Consistent findings on the value of cooperative goals and problem solving could form the basis for a common framework for people with diverse cultural backgrounds in such settings as international joint ventures to learn from their mistakes together (Cox et al., 1991).

The Chinese setting may provide a strong test of the hypotheses. Previous research suggests that open, problem solving approaches are often easily experienced as threats in collectivist China (Chan, 1963; Triandis et al., 1990; Tse et al., 1994). However, some evidence suggests that Chinese people welcome open discussions, at least when skilfully and respectfully conducted (Tjosvold and Sun, 2003).

\section{METHODS}

\section{Participants}

As the hypotheses indicated that the group should be the unit of analysis, teams from organizations in Shanghai were recruited to participate in the study. In addition to obtaining the approval of top and middle management for teams to participate in the study, teams were assured that their responses would be kept confidential.

We distributed 170 sets of questionnaires and collected 149 sets. However, a number of questionnaires were discarded because they did not include a completed questionnaire from the manager and questionnaires from at least two team members. The final sample was 107 teams with one manager and two team members. The average age of the team members was 33 and $70 \%$ of the team members were males. Nearly all respondents had been in their teams for over six months. Most teams had ten or fewer members. 
In order to strengthen the generalizability of the findings, we wanted the final sample of teams to be diverse in terms of tasks and functions. Seventy four per cent of the teams were involved with the central business of the organization, e.g. production in power companies, underwriter and investment banking in insurance companies, manufacturing and product research in manufacturing companies, and marketing in real estate companies. In addition, 9 per cent of the teams were involved in accounting and another 9 per cent in administration, and 8 per cent of the teams provided supervision.

Also to improve generalizability, we wanted the final sample to be from organizations that represented the industrial structure of Shanghai, China. Most of the participating teams were from the industries of Transportation, Manufacturing and Finance, as those is the largest industries in Shanghai, but there was at least one team from every industrial sector. Teams were primarily from large scale ventures and medium ventures, as these are the most prevalent in Shanghai. Most teams were from private enterprises, which is also consistent with the Shanghai economy.

The study makes methodological contributions to previous research in that it allowed independent measures. Team members rated how their goals were related and problem solving and blaming orientations and they and their managers rated the team's abilities to learn from mistakes.

\section{Interdependence and Interaction Measures}

Scales for cooperative, competitive, and independent goals were developed from a previous questionnaire study conducted in North America (Alper et al., 1998). The cooperative goal scale measured the emphasis on compatible, mutual goals. A sample item from the five item cooperative goal scale was 'The goals of team members go together'. Participants were asked to rate on a 7 -point scale $(1=$ strongly disagree, $7=$ strongly agree) their level of agreement to the five statements. (The Appendix has the items for all scales.) The coefficient alpha for the cooperative goals scale was 0.82 .

The competitive goal scale had five items with similar anchors to measure the emphasis on incompatible goals. A sample item was 'Team members' goals are incompatible with each other'. The coefficient alpha was 0.70 .

The independent goal scale had six items with similar anchors to measure the emphasis on unrelated goals. A sample item was 'One team member's success is unrelated to others success'. The coefficient alpha was 0.67 . A previous study had found reliabilities of the three scales to be $0.81,0.72$ and 0.78 , respectively (Alper et al., 1998).

A problem solving orientation involves trying to understand the barriers that are frustrating performance and developing alternative ways that may be more successful. Group members responded to a slightly modified 6-item scale to 
measure their group's problem solving orientation (Van Dyck et al., 1998). Respondents were asked to answer on a 7 -point scale $(1=$ strongly disagree; $7=$ strongly agree) about their level of agreement with the six statements. A sample item from the scale was 'After a mistake has been made, we analyse it thoroughly'. The coefficient alpha of the scale was 0.91. Previous research found alphas of 0.72 and 0.76 for the problem solving scale from which this study's scale was developed (Rybowiak et al., 1998).

A blaming orientation involves the attempt to assign responsibility for difficulties on others and to avoid the costs for being held responsible for a mistake. Group members rated their blaming orientation on an 8-item scale taken from Van Dyck et al. (1998) (Appendix). A sample item was 'Our motto is: "Blame someone else when a mistake is made"'. The coefficient alpha of the scale was 0.74 . Previous research found alphas of 0.84 and 0.83 for the blaming orientation scale from which this study's scale was developed (Rybowiak et al., 1998).

\section{Outcome Measures}

As with other work team research (Cohen and Ledford, 1994; Goodman et al., 1988), obtaining objective work outcome measures proved impossible. Companies did not collect team level productivity data. Therefore, group members and their managers provided ratings of learning from mistakes as criterion measures.

Group members indicated on a 7-point scale the extent that their team was able to learn from their mistakes. A sample item was 'In mastering our tasks, team members learn a lot from their mistakes'. The coefficient alpha of the scale was 0.90. Previous research found alphas of 0.78 and 0.89 for the scale from which this study's scale was developed (Rybowiak et al., 1998).

In order to reduce the possibility of common method variance, managers who are likely to be informed about the outcomes of each team were also asked to respond to this 6-item scale. Proposing that there is no strictly objective measure of performance in organizations, Pritchard (1992) argued that ratings can measure the extent to which users of the team outputs find them effective. In addition, these managers should be informed about the group's performance (Hackman, 1987). The coefficient alpha for the manager ratings on learning from mistakes scale was 0.83 .

Two native Chinese members of the research team translated the questionnaires originally written in English into Chinese. To ensure conceptual consistency, the questionnaires were translated back into English to check for possible deviation (Brislin, 1970).

The questionnaires were pre-tested to make sure that respondents clearly understood every phrase, concept, and question. The original questionnaire was piloted on several employees who were not part of the final sample. They indicated that they found it difficult to recall mistakes. The introduction was modified to suggest 
that the respondents first reflect upon specific times when their group was confronted with a mistake. They were asked to recall the issues involved in these incidents and how the team discussed them. Another group of employees completed the new questionnaire but they indicated that it had too many items. Several scales were shortened and a third questionnaire was developed that was used in the study. To reduce potential concern for being involved in evaluating others, participants were assured that their responses would be held totally confidential.

\section{ANALYSIS}

\section{Data Aggregation}

We aggregated team members' ratings of cooperative goals, competitive goals, independent goals, problem solving orientation, blaming orientation, and learning from mistakes by group members to the team level of analyses. The fundamental reason was that the hypotheses identified the group as the unit of analysis. The operations were carefully constructed and individual team members reported on the team's six scales. Managers also reported on the group's learning from mistakes.

However, the aggregation required that the perceptions of team members within a team were reasonably homogeneous. We used James et al.'s (1984) procedure to estimate the inter-rater reliability of members within each team for each of the two individual-level variables. James et al.'s $r_{W G(J)}$ index was used as an estimate of inter-rater reliability because each of the two variables was measured by multiple items. Two indicators showed that the ratings among members in each group were quite homogeneous. The median $\mathrm{r}_{\mathrm{WG}(\mathrm{J})}$ for the six variables across the 107 teams were 0.96, 0.97, 0.98, 0.97, 0.98, and 0.98 respectively. George and Bettenhausen (1990) argued that $r_{\mathrm{WG}(\mathrm{J})}$ which was greater than or equal to 0.70 could be considered as indicators of good agreement within the group. Out of the 107 teams, the percentages of teams with $r_{\mathrm{WG}(\mathrm{J})}$ greater than or equal to 0.70 across the six variables were $0.93,0.95,0.96,0.95,0.97$ and 0.96 respectively. We therefore concluded that the within-team ratings were homogeneous enough to be aggregated to the team level. Individual team members' ratings were therefore aggregated to the team level and the data merged with managerial ratings of learning from mistakes. The final sample size of the merged data file was 107 teams.

\section{Scale Validation}

Although most of the items used in this study were validated previously, we were still cautious and tested the factorial structure of the measurement items. We conducted a series of confirmatory factor analyses to test whether the team members' ratings would load on seven distinct factors, namely cooperative (GOO), competi- 
Table I. Correlations among variables at the team level

\begin{tabular}{lccccccccc}
\hline \hline Variables & Mean & SD & Coop & Comp & Indep & $\begin{array}{c}\text { Problem } \\
\text { solving }\end{array}$ & Blaming & $\begin{array}{c}\text { Learning } \\
\text { by group }\end{array}$ & $\begin{array}{c}\text { Learning } \\
\text { by manager }\end{array}$ \\
\hline Cooperation & 5.32 & 0.81 & $(0.82)$ & & & & & & \\
$\begin{array}{l}\text { Competition } \\
\text { Independence }\end{array}$ & 3.49 & 0.73 & $-0.30^{* *}$ & $(0.70)$ & & & & & \\
$\begin{array}{c}\text { Problem } \\
\text { solving }\end{array}$ & 5.42 & 0.69 & -0.07 & $0.62^{* *}$ & $(0.67)$ & & & & \\
$\begin{array}{c}\text { Blaming } \\
\text { Learning by } \\
\text { group }\end{array}$ & 5.96 & 0.66 & $-0.63^{* *}$ & -0.18 & -0.02 & $(0.91)$ & & & \\
$\begin{array}{c}\text { Learning by } \\
\text { manager }\end{array}$ & 5.68 & 0.73 & $0.65^{* *}$ & -0.02 & 0.15 & $0.73^{* *}$ & -0.06 & $(0.90)$ & \\
\hline \hline
\end{tabular}

Notes:

$\mathrm{N}=107$.

Values in parentheses are reliability (coefficient alpha) estimates.

$* * \mathrm{p}<0.01 ; * \mathrm{p}<0.05$.

tive (COM) and independent (IND) goals, problem solving orientation (PSO), blaming orientation (BO), learning from mistakes by group (LFMG) and learning from mistakes by manager (LFMM). These series of confirmatory factor analyses were conducted at the team level ( $\mathrm{N}=107$ teams) as the team is the level of analysis.

The confirmatory factor analyses were conducted using EQS (5.7). Because of computational limitations for structural equation models involving a number of indicators (Bentler and Chou, 1987), we simplified the structural model in the present study by reducing the number of indicators for the constructs. Specifically, we combined the items with the highest and the lowest loading by averaging until there were three indicators for each construct. That is, the items with highest and the lowest loadings were averaged to form a first new indicator, and the items with the next highest and the next lowest loadings were averaged to form the second new indicator, etc. This is a common approach in the literature of structural equation analysis and was used in Mathieu and Farr (1991) and Mathieu et al. (1993).

We compared the 7-factor model, labelled as $\mathrm{M}_{0}$, with four alternative 6-factor models in testing the factorial structure of the items: $\mathrm{M}_{1}, \mathrm{M}_{2}, \mathrm{M}_{3}, \mathrm{M}_{4}$. These alternative 6-factor models tested if the respondents would be able to distinguish the two correlated measures in their responses and if the two measures should be combined. $\mathrm{M}_{1}$ combined the indicators of $\mathrm{COO}$ and PSO. $\mathrm{M}_{2}$ combined the indicators of $\mathrm{COO}$ and LMFG. $\mathrm{M}_{3}$ combined the indicators of COM and IND. Finally, $\mathrm{M}_{4}$ combined the indicators of PSO and LMFG to form a new latent variable. 
Table II. Confirmatory factor analysis of the measurement models

\begin{tabular}{llll}
\hline \hline & d.f. & Model $c^{2}$ & $D c^{2}$ \\
\hline Baseline 7-factor model $\left(\mathbf{M}_{0}\right)$ & 642 & 1064.50 & \\
Combined $\left(\mathbf{M}_{1}\right)$ & 657 & 1139.83 & $75.33^{* *}$ \\
Combined $\left(\mathbf{M}_{2}\right)$ & 657 & 1139.54 & $75.04^{* *}$ \\
Combined $\left(\mathbf{M}_{3}\right)$ & 657 & 1120.55 & $56.05^{* *}$ \\
Combined $\left(\mathbf{M}_{4}\right)$ & 657 & 1118.74 & $54.24^{* *}$ \\
\hline \hline
\end{tabular}

Notes:

$* * \mathrm{p}<0.01$.

$\chi^{2}$ is the model chi-square, $\mathrm{D} \chi^{2}$ is the change in model chi-square; Dd.f. $=$ 657 for all three alternative models.

Results of this series of confirmatory factor analyses are shown in Table II. The changes in model chi-square for all four alternative models were significant at the 0.01 level. We were, therefore, confident that the seven constructs used in this study were capturing unique variances and were distinctive psychological constructs.

\section{Hypotheses Testing}

Correlational analyses were used as an initial examination of the hypotheses. To more vigorously test the proposed model that problem solving and blaming orientations mediate the relationship between how goals are related and the team abilities to learn from mistakes, structural equation analysis with the EQS for Macintosh program was used (Bentler and Wu, 1995). The Mediating Effects model suggested by the theory implies that there should be no direct effects between how goals are related and the team abilities to learn from mistakes. Problem solving and blaming orientations mediate the relationship between how goals are related and the team abilities to learn from mistakes. A nested model test commonly adopted in causal model analysis was used where the Mediating Effects model was compared to the Full Effects model and the Direct Effects model. The Full Effects model includes both the direct and the mediating effects on the outcome variables. The Direct Effects model posited that cooperative, competitive, and independent goals impact outcomes directly. The Indirect Effects model gains the strongest support if it contributes significantly to the fit of the Full Effects model and if the Direct Effects model did not contribute significantly to the fit of the Full Effects model. A particular effect contributes significantly to the fit of the Full Effects model if the removal of the effect results in significant change in the nested model test. 


\section{RESULTS}

Zero-order correlations provide an initial examination of the hypotheses linking cooperative goals, competitive goals, independent goals, problem solving orientation, blaming orientation, and learning from mistakes (Table I). However, hypothesis one was not supported. A blaming approach was not significantly related to learning from mistakes as rated by their managers $(r=-0.06)$ or by group members $(r=0.07)$. In support of hypothesis two, groups that reported a problem solving approach learned from their mistakes measured both by ratings of their managers $(\mathrm{r}=0.46, \mathrm{p}<0.01)$ and group members $(\mathrm{r}=0.73, \mathrm{p}<0.01)$.

Results are consistent with Hypothesis 3 in that cooperative goals were positively related to group problem solving $(\mathrm{r}=0.63, \mathrm{p}<0.01)$. Findings also support Hypotheses 4 and 5 in that competitive $(r=0.39, p<0.01)$ and independent goals $(\mathrm{r}=0.31, \mathrm{p}<0.01)$ were related to blaming within groups.

Structural equation analyses were used to examine possible causal relationships. The Indirect Effects and the Direct Effects models were compared to the Full Effects model (with both the mediating effects and the direct effects of three goals). The $\chi^{2}$ of the Full model was 5.2 with 1 degree of freedom. The $\chi^{2}$ of the Indirect Effects model was 35.11 (d.f. $=7, \mathrm{p}<0.01$ ). The $\chi^{2}$ of the Direct Effects model was 121.66 (d.f. $=11, \mathrm{p}<0.01$ ). The difference between the Indirect Effects model and the Direct Effects model was significant $\left(\chi^{2}\right.$ difference $\left.=86.55, \mathrm{p}<0.01\right)$, indicating that the omission of the mediating effects of cooperative, competitive, and independent goals significantly deteriorated the Indirect Effects model. The difference between the Full and Indirect Effects models was also significant $\left(\chi^{2}\right.$ difference $=29.91, \mathrm{p}<0.01)$, indicating that omission of the cooperative, competitive, and independent goals paths directly to learning significantly deteriorated the Full Effects model. Results of the causal model comparison suggest the usefulness of the Indirect Effects model compared to the Direct Effects model but also that the Full Effects model be accepted.

The path coefficients of the theorized model help to explore the findings more specifically (Table III). Cooperative goals had a significant relationship with group problem solving $(\beta=0.63, \mathrm{p}<0.01)$. Competitive goals had a significant relationship with blaming orientation $(\beta=0.31, \mathrm{p}<0.01)$. Problem solving orientation had a significant relationship with learning from mistakes rated both by managers $(\beta=0.50, \mathrm{p}<0.01)$ and by group members $(\beta=0.76, \mathrm{p}<0.01)$. In addition, blaming orientation had a positive relationship with learning from mistakes rated by managers $(\beta=0.19, \mathrm{p}<0.05)$ and by group members $(\beta=0.11, \mathrm{p}<0.10)$. These findings on path coefficients provide good support for most of the study's hypotheses. In addition, the Full Effects model indicated that cooperative goals had a significant effect on learning from mistakes as measured by the group members and managers $(\beta=0.40, \mathrm{p}<0.01, \beta=0.29, \mathrm{p}<0.01)$. Path estimates along with the analysis of the structural equation models suggest that cooperative 
Table III. Results of the nested model analyses

\begin{tabular}{|c|c|c|c|c|c|}
\hline \multicolumn{2}{|c|}{ Indirect effects model } & \multicolumn{2}{|l|}{ Direct effects model } & \multicolumn{2}{|l|}{ Full model } \\
\hline Path & $\begin{array}{l}\text { Path } \\
\text { coefficient }\end{array}$ & Path & $\begin{array}{l}\text { Path } \\
\text { coefficient }\end{array}$ & Path & $\begin{array}{l}\text { Path } \\
\text { coefficient }\end{array}$ \\
\hline Coop PSO & $0.63^{* *}$ & Coop LFM-G & $0.69^{* *}$ & Coop PSO & $0.63^{* *}$ \\
\hline Comp PSO & -0.02 & Comp LFM-G & 0.10 & Comp PSO & -0.02 \\
\hline Indep PSO & 0.03 & Indep LFM-G & 0.14 & Indep PSO & 0.03 \\
\hline Coop BO & -0.02 & Coop LFM-M & $0.48^{* *}$ & Coop BO & -0.02 \\
\hline Comp BO & $0.31^{* *}$ & Comp LFM-M & -0.04 & Comp BO & $0.31 * *$ \\
\hline Indep BO & 0.11 & Indep LFM-M & 0.05 & Indep BO & 0.11 \\
\hline PSO LFM-G & $0.76^{* *}$ & & & PSO LFM-G & $0.53^{* *}$ \\
\hline BO LFM-G & $0.11^{\#}$ & & & BO LFM-G & 0.04 \\
\hline PSO LFM-M & $0.50^{* *}$ & & & Coop LFM-G & $0.40^{* *}$ \\
\hline \multirow[t]{3}{*}{ BO LFM-M } & $0.19 *$ & & & Comp LFM-G & 0.10 \\
\hline & & & & Indep LFM-G & 0.12 \\
\hline & & & & PSO LFM-M & \\
\hline \multicolumn{6}{|l|}{$0.031 * *$} \\
\hline & & & & BO LFM-M & $0.21 *$ \\
\hline & & & & Coop LFM-M & $0.29 * *$ \\
\hline & & & & Comp LFM-M & -0.10 \\
\hline & & & & Indep LFM-M & 0.02 \\
\hline Model $\chi^{2}$ & 35.11 & Model $\chi^{2}$ & 121.66 & Model $\chi^{2}$ & 5.2 \\
\hline d.f. & 7 & d.f. & 11 & d.f. & 1 \\
\hline BBNFI & 0.88 & BBNFI & 0.59 & BBNFI & 0.98 \\
\hline CFI & 0.90 & CFI & 0.60 & CFI & 0.99 \\
\hline
\end{tabular}

Notes:

$\mathrm{N}=107$.

$\# \mathrm{p}<0.10 ; * * \mathrm{p}<0.01 ; \mathrm{p}<0.05$.

goals and problem solving orientation can be quite useful for understanding a team's ability to learn from mistakes.

\section{DISGUSSION}

Learning from mistakes is highly useful for helping organizations adapt and respond to the rapid changes in the marketplace where miscalculations and errors are likely and costly (Buffardi et al., 2000). Mistakes are important opportunities for organizational members to understand and incorporate new ideas into their thinking and behaviour. Results of this study confirm the theorizing that interdependence and interaction can have major effects on learning (Fisher and White, 2000; Lane and Lubatkin, 1998; Senge, 1990) and recent research suggesting the value of team level variables (Cannon and Edmondson, 2001; Edmondson, 1999). Although employing a different theoretical perspective and empirical methods, results support Arygris and Schon's (1978, 1996) position that openness and 


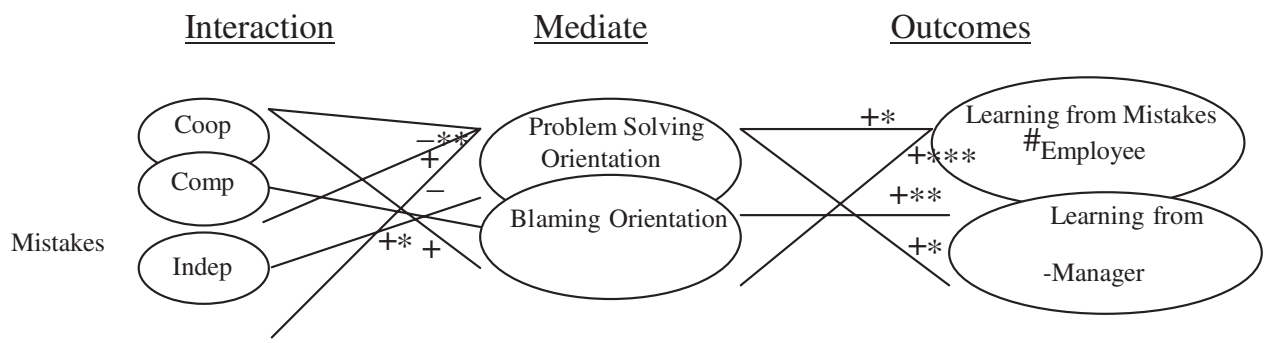

Figure 1. Hypothesized model

$\#$ p $<0.10 ; * *$ p $<0.01 ; *$ p $<0.05$.

mutuality are critical conditions for learning. Results empirically link the theory and research on cooperation and competition with the organizational learning literature. Specifically, findings suggest that cooperative goals within a team may be a foundation for the problem-solving interaction among members that helps teams learn from their mistakes.

Problem solving where team members recognize that mistakes can help them improve and together analyse, discuss, and plan how to correct them, was found to be an important antecedent of learning from mistakes from both the perspective of group members and their managers. The structural equation analyses support the proposition that team members who believed that their goals were compatible where they had a feeling of being in this together were likely to adopt this problem solving orientation (Deutsch, 1973; Johnson and Johnson, 1989; Tjosvold, 1998). Indeed, cooperative goals were so important that the nesting model analysis suggested that they also had a direct effect on team learning as measured by both group members and managers. Problem solving did not fully mediate the relationship between cooperative goals and learning. Competitive goals were negatively related to problem solving.

Results on blaming were not nearly as strong as those on problem solving and did not support the hypothesis that blaming would interfere with learning, nor did they provide much support that blaming facilitates learning. Blaming, along with competitive and independent goals, were found to have statistically non-significant relationships with learning in the correlational analyses, although blaming did have positive effects on learning in the structural equation analyses.

Blaming and problem solving were negatively correlated; cooperative goals predicted to problem-solving and competitive goals to blaming. However, results overall suggest that blaming is not just a mirror image of problem solving. Whereas problem solving clearly predicted to learning from mistakes, results on blaming were more mixed.

Although the non-significant correlations of blaming and learning may be due to measurement errors, it can be speculated that blaming may have a mixed relationship with learning. Blaming may indeed increase defensiveness and closed- 
mindedness, especially when it is done covertly and is considered not discussible (Arygris and Schon, 1978, 1996). However, blaming, especially when it is done openly, may also promote responsibility and accountability. Recent studies have emphasized that holding individuals accountable can promote teamwork and decision-making (Lerner and Tetlock, 1999; Peterson and Thompson, 1997). Team members recognize that errors will not be quietly forgotten but will be noted and individuals held accountable. Under these conditions, team members may be particularly eager to try to learn. However, the blaming also leads to efforts to hide mistakes and hold others accountable if possible.

It can be speculated that combining problem solving and holding individuals accountable may be particularly facilitative to learning from mistakes. Future research is needed to clarify the role of blaming and the conditions under which it leads to learning or defensiveness. Indeed, previous research has suggested that blaming is a common approach to interpersonal problems in China (Weldon and Jehn, 1993).

Learning from mistakes would appear to be especially important for top management teams (TMT) to help them continuously refine their organizations' strategies. However, researchers have portrayed TMTs as typically defensive and closed minded, even willing to pursue misguided strategies that prove disastrous (Argyris and Schon, 1996; Bazerman, 1997; Li et al., 1999; Staw, 1981). Results of this study suggest that TMTs will blame each other rather than solve problems to the extent that their members have competitive goals. Future research could directly establish the extent that cooperative goals and problem solving help TMTs learn from mistakes and whether this learning in turn facilitates their organization's performance.

Theories developed in one culture cannot be assumed to apply in another (Hofstede, 1993). However, the results suggest that the concepts of problem solving, cooperation, and competition can be useful for understanding learning from mistakes in Chinese organizations. Findings challenge the general belief that open, problem solving discussions in China are inappropriate because they disrupt relationships. Open discussions of problems with a background of cooperative goals appear to be quite useful for teamwork in China.

\section{Practical Implications}

Teamwork within and between organizations has become increasingly recognized as critical for learning. Results of this study reaffirm the value of open, problem solving discussions of issues and difficulties. However, avoidance and blaming are common in many organizations, even in the West (Katzenbach and Smith, 1993; Pfeffer and Veiga, 1999).

Results of this study, if replicated and extended, have potentially important implications in that they indicate that cooperative goals can promote problem 
solving discussions that help teams and organizations learn from mistakes. Training for errors can explicitly include developing the cooperative goals that appear to be a foundation for learning from mistakes (Heimbeck et al., 2003). Previous research suggests that common tasks and shared rewards can help team members believe that their goals are cooperative (Tjosvold and Tjosvold, 1995). Norms can encourage group members to dig into issues by expressing their opinions and inviting others to discuss theirs (Cannon and Edmondson, 2001). They recognize the common value of discussing problems. They seek to understand each other, recognize that they want to resolve the issue so they can make a mutually advantageous decision and accomplish common tasks, and create new, useful solutions to do so.

Previous research has suggested that team-level variables can be highly useful for learning from, and reducing, mistakes (Zohar, 2000). In particular, teams that develop a common understanding of the value of open discussion for solving problems and have the psychological safety to discuss errors may overcome barriers and learn from mistakes (Cannon and Edmondson, 2001; Edmonson, 1999). Results of this study help to specify the nature of this common understanding by suggesting that a problem solving approach and cooperative goals are important bases for learning from mistakes. A future research challenge is to test these ideas directly in international alliances. This research could demonstrate that cooperative goals and problem solving are useful for Chinese and Western partners to learn from the inevitable mistakes incurred in international alliances (Kale et al., 2000).

The theory of cooperation and competition and its considerable research conducted in many classroom settings has stimulated educational reform and teacher education (Johnson and Johnson, 1999). This study empirically links the theory of cooperation and competition with the organizational learning literature. Its findings suggest the conditions when organizational teams are able to overcome barriers to analyse mistakes and create viable solutions. Developing strong cooperative goals among group members can help them discuss their mistakes so that they develop new approaches that reduce the probability of future errors.

\section{NOTE}

*This work has been supported by the Research Grants Council of the Hong Kong Special Administrative Region, China (Project No: LU3013/01H) to the first author. We appreciate the able assistance of Helen Liu, Sofia Su Fang, Wan Jieping, and Xu Weishan Wally.

\section{APPENDIX: SGALES AND ITEMS}

\section{Cooperative Goals}

Our team members 'swim or sink' together.

Our team members want each other to succeed.

Our team members seek compatible goals. 
Our team members' goals go together.

When our team members work together, we usually have common goals.

\section{Competitive Goals}

Team members structure things in ways that favour their own goals rather than the goals of other team members.

Team members have a 'win-lose' relationship.

Team members like to show that they are superior to each other.

Team members' goals are incompatible with each other.

Team members give high priority to the things they want to accomplish and low priority to the things other team members want to accomplish.

\section{Independent Goals}

Each team member 'does his/her own thing'.

Team members like to be successful through their own individual work.

Team members work for their own independent goals.

One team member's success is unrelated to others' success.

Team members like to get their rewards through their own individual work.

Team members are most concerned about what they accomplish when working by themselves.

\section{Problem-Solving Approach}

After a mistake has been made, we analyse it thoroughly.

Team members work to use their mistakes to make progress.

In this team mistakes are discussed so that we can correct them.

Because mistakes provide important information for how we can complete our work, we discuss them.

When a team member makes an error, they share it with others so that they don't make the same mistake again.

After an error, people think through how to correct it.

\section{Blaming Approach}

In this team people are punished for their mistakes.

People in this team are afraid of making mistakes.

In general people feel embarrassed after making a mistake.

People in this team are relieved if someone else, rather than they themselves, makes an error.

We cannot just let negative feelings associated with mistakes go away. 
Our motto is: 'Blame someone else when a mistake is made'.

It can be painful to make your mistakes known to team members.

Team members often find it advantageous to cover-up their mistakes.

\section{Members' Rating of Learning from Mistakes}

Mistakes are very useful for improving our team's work process.

A mistake provides important information to solve the issue at hand.

Our mistakes point us to how we can improve.

In mastering our tasks, team members learn a lot from their mistakes.

We learn from mistakes.

We do not let mistakes recur unnecessarily.

We can correct most mistakes effectively.

\section{Managers' Ratings of Learning from Mistakes}

Mistakes are very useful for improving this team's work process.

A mistake provides important information for the team to solve the issue at hand.

The team's mistakes point us to how they can improve.

In mastering their tasks, team members learn a lot from their mistakes.

Team members learn from mistakes.

Team members do not let mistakes recur unnecessarily.

\section{REFERENGES}

Adler, P. S. and Kwon, S. W. (2002). 'Social capital: prospects for a new concept'. Academy of Management Review, 27, 17-40.

Akbar, H. (2003). 'Knowledge levels and their transformation: Towards the integration of knowledge creation and individual learning'. Fournal of Management Studies, 40, 8, 1997-2021.

Alicke, M. (2000). 'Culpable control and the psychology of blame'. Psychological Bulletin, 126, $556-74$.

Alper, S., Tjosvold, D. and Law, S. A. (1998). 'Interdependence and controversy in group decision making: antecedents to effective self-managing teams'. Organizational Behavior and Human Decision Processes, 74, 33-52.

Arygris, C. and Schon, D. A. (1978). Organizational Learning: A Theory of Action Perspective. Reading, MA: Addison-Wesley.

Arygris, C. and Schon, D. A. (1996). Organizational Learning II: Theory, Method, and Practice. Reading, MA: Addison-Wesley.

Barker, J., Tjosvold, D. and Andrews, I. R. (1988). 'Conflict approaches of effective and ineffective managers: a field study in a matrix organization'. Fournal of Management Studies, 25, 167-78.

Barling, J., Loughlin, C. and Kelloway, E. K. (2002). 'Development and test of a model linking safetyspecific transformational leadership and occupational safety'. Fournal of Applied Psychology, 87, 488-96.

Bazerman, M. (1997). Judgment in Managerial Decision Making, 4th edition. New York: John Wiley.

Bentler, P. M. and Chou, C. P. (1987). 'Practical issues in structural modeling'. Sociological Methods \& Research, 16, 78-117.

Bentler, P. M. and Wu, E. J. C. (1995). EQS for Macintosh User's Guide. Encino, CA: Multivariate Software, Inc. 
Brislin, R. W. (1970). 'Back-translation for cross-cultural research'. Fournal of Cross-Cultural Psychology, 1, 185-216.

Buffardi, L. C., Fleishman, E. A., Morath, R. A. and McCarthy, P. M. (2000). 'Relationships between ability requirements and human errors in job tasks'. Fournal of Applied Psychology, 85, $551-64$.

Cannon, M. and Edmondson, A. (2001). 'Confronting failure: antecedents and consequences of shared beliefs about failure in organizational work groups'. Fournal of Organizational Behavior, 22, $161-77$.

Carter, S. M. and West, M. A. (1998). 'Reflexivity, effectiveness, and mental health in BBC-TV production teams'. Small Group Research, 29, 583-601.

Chan, W. T. (1963). A Source Book in Chinese Philosophy. Princeton, NJ: Princeton University Press.

Cohen, S. G. and Ledford, G. E. Jr (1994). 'The effectiveness of self-managing teams: a quasiexperiment'. Human Relations, 47, 13-43.

Cox, T. H., Lobel, S. A. and McLeod, P. L. (1991). 'Effects of ethnic group cultural differences on cooperative and competitive behavior on a group task'. Academy of Management Fournal, 34, $827-47$

Crossan, M. M., Lane, H. W. and White, R. E. (1999). 'An organizational learning framework: from intuition to institution'. Academy of Management Review, 24, 522-37.

De Dreu, C. and Van de Vliert, E. (Eds) (1997). Using Conflict in Organizations. Thousand Oaks, CA: Sage.

Deutsch, M. (1949). 'A theory of cooperation and competition'. Human Relations, 2, 129-52.

Deutsch, M. (1962). 'Cooperation and trust: some theoretical notes'. In Jones, M. R. (Ed.), Nebraska Symposium on Motivation. Lincoln, NE: University of Nebraska Press, 275-319.

Deutsch, M. (1973.). The Resolution of Conflict. New Haven, CT: Yale University Press.

Ding, D. Z. (1995) 'In Search of Determinants of Chinese Conflict Management Styles in Joint Ventures: An Integrated Approach'. Paper presented at the Thirteenth Annual Conference of the Association of Management, Vancouver, Canada.

Druskat, V. U. and Kayes, D. C. (2000). 'Learning versus performance in short-term project teams'. Small Group Research, 31, 328-53.

Dweck, C. S. and Leggett, E. L. (1988). 'A social-cognitive approach to motivation and personality'. Psychological Review, 95, 256-73.

Edmondson, A. (1996). 'Learning from mistakes is easier said than done: group and organizational influences on the detection and correction of human error'. Fournal of Applied Behavioral Science, 32, 1, 5-28.

Edmondson, A. C. (1999). 'Psychological safety and learning behavior in work teams'. Administrative Science Quarterly, 44, 350-83.

Eliott, E. S. and Dweck, C. S. (1988). 'Goals: an approach to motivation and achievement'. Fournal of Personality and Social Psychology, 54, 5-12.

Ely, R. J. and Thomas, D. A. (2001). 'Cultural diversity at work: the effects of diversity perspectives on work group processes and outcomes'. Administrative Science Quarterly, 46, 229-73.

Fisher, S. R. and White, M. A. (2000). 'Downsizing in a learning organization: are there hidden costs?'. Academy of Management Review, 25, 244-51.

Folger, R. and Skarlicki, D. P. (1998). 'When tough times make tough bosses: managerial distancing as a function of layoff blame'. Academy of Management fournal, 41, 79-87.

George, J. M. and Bettenhausen, K. (1990). 'Understanding prosaic behavior, sales performance, and turnover: a group-level analysis in a service context'. Fournal of Applied Psychology, 75, 698-709.

Goodman, P. S., Devadas, R. and Griffith-Hughson, T. L. (1988). 'Groups and productivity: analyzing the effectiveness of self-managing teams'. In Campbell, J. P. and Campbell, R. J. (Eds), Productivity in Organizations: New Perspectives from Industrial and Organizational Psychology. San Francisco, CA: Jossey-Bass, 295-327.

Hackman, J. R. (1987). 'The design of work teams'. In Lorsch, J. (Ed.), Handbook of Organizational Behavior. Englewood Cliffs, NJ: Prentice Hall, 315-42.

Heimbeck, D., Frese, M., Sonnentag, S. and Keith, N. (2003). 'Integrating errors into the training process: the function of error management instructions and the role of goal orientation'. Personnel Psychology, 56, 333-61.

Hofstede, G. (1993). 'Cultural constraints in management theories'. The Academy of Management Executive, 7, 81-94. 
Houghton, S. M., Simon, M. and Goldberg, C. B. (2000). 'No safety in numbers: persistence of biases and their effects on team risk perception and team decision making'. Group and Organization Management, 25, 325-53.

James, L. R., Demaree, R. G. and Wolf, G. (1984). 'Estimating within-group interrater reliability with and without response bias'. Fournal of Applied Psychology, 69, 85-98.

Jazabkowski, P. and Wilson, D. C. (2002). 'Top teams and strategy in a UK university'. Fournal of Management Studies, 39, 3, 355-81.

Johnson, D. W. and Johnson, R. T. (1989). Cooperation and Competition: Theory and Research. Edina, MN: Interaction Book Company.

Johnson, D. W. and Johnson, R. (1999). Learning Together and Alone: Cooperative, Competitive, and Individualistic Learning, 5th edition. Boston, MA: Allyn and Bacon.

Johnson, D. W., Maruyama, G., Johnson, R. T., Nelson, D. and Skon, S. (1981). 'Effects of cooperative, competitive, and individualistic goal structures on achievement: a meta-analysis'. Psychological Bulletin, 89, 47-62.

Kale, P., Singh, H. and Perlmutter, H. (2000). 'Learning and protection of proprietary assets in strategic alliances: building relational capital'. Strategic Management Fournal, 21, 217-37.

Katzenbach, J. R. and Smith, D. K. (1993). The Wisdom of Teams: Creating the High-Performance Organization. Boston, MA: Harvard Business School Press.

Kelman, H. C. (1997). 'Group processes in the resolution of international conflicts: experiences form the Israeli-Palestinian case'. American Psychologist, 52, 212-20.

Kraatz, M. S. (1998). 'Learning by association? Interorganizational networks and adaptation to environmental change'. Academy of Management Fournal, 41, 621-43.

Lane, P. J. and Lubatkin, M. (1998). 'Relative absorptive capacity and interorganizational learning'. Strategic Management fournal, 19, 461-77.

Lerner, J. S. and Tetlock, P. E. (1999). 'Accounting for the effects of accountability'. Psychological Bulletin, 125, 255-75.

Levitt, B. B. and March, J. G. (1988). 'Organizational learning'. Annual Review of Sociology, 14, 319-40.

Li, J., Xin, K. R., Tsui, A. and Hambrick, D. C. (1999). 'Building effective international joint venture leadership teams in China'. Fournal of World Business, 34, 52-68.

Luo, Y. and Peng, M. W. (1999). 'Learning to compete in a transition economy: experience, environment, and performance'. Fournal of International Business Studies, 30, 269-96.

Maier, N. R. F. (1952). Principles of Human Behavior. New York: Wiley.

Mathieu, J. E. and Farr, J. L. (1991). 'Further evidence for the discriminant validity of measures of organizational commitment, job involvement, and job satisfaction'. Fournal of Applied Psychology, 76, $127-33$.

Mathieu, J. E., Hofmann, D. A. and Farr, J. L. (1993). 'Job perception-job satisfaction relations: an empirical comparison of three competing theories'. Organizational Behavior and Human Decision Processes, 56, 370-87.

Nonaka, I. and Takeuchi, H. (1995). The Knowledge Creating Company. Oxford: Oxford University Press.

Pfeffer, J. and Veiga, J. F. (1999). 'Putting people first for organizational success'. The Academy of Management Executive, 13, 37-48.

Peterson, E. and Thompson, L. (1997). 'Negotiation teamwork: the impact of information distribution and accountability on performance depends on the relationship among team members'. Organizational Performance and Human Decision Processes, 72, 364-83.

Pritchard, D. (1992). 'Organizational productivity'. In Dunnette, M. D. and Hough, L. M. (Eds), Handbook of Industrial and Organizational Psychology, Vol. 3. Palo Alto: Consulting Psychologists Press, 443-71.

Pruitt, D. G. and Syna, H. (1989). 'Successful problem solving'. In Tjosvold, D. and Johnson, D. W. (Eds), Productive Conflict Management: Perspectives for Organizations. Minneapolis, MN: Team Media, 69-90.

Rybowiak, V., Garst, H., Frese, M. and Batinic, B. (1998). 'Error orientation questionnaire (EOQ): reliability, validity, and different language equivalence'. Fournal of Organizational Behavior, 20, $527-47$.

Rubin, J. Z., Pruitt, D. G. and Kim, S. H. (1994). Social Conflict: Escalation, Stalemate, and Settlement, 2nd edition. New York: McGraw-Hill.

Schwenk, C. R. (1984). 'Cognitive simplification processes in strategic decision-making'. Strategic Management fournal, 5, 111-28. 
Senge, P. (1990). The Fifth Discipline: The Art and Practice of the Learning Organization. New York: Doubleday/Currency.

Simonin, B. L. (1997). 'The importance of collaborative know-how: an empirical test of the learning organization'. Academy of Management Fournal, 40, 1150-74.

Stanne, M., Johnson, D. W. and Johnson, R. (1999). 'Social interdependence and motor performance: a meta-analysis'. Psychological Bulletin, 125, 1, 133-54.

Starkey, K. (1998). 'What can we learn form the learning organization?'. Human Relations, 51, 531-46.

Staw, B. M. (1981). 'The escalation of commitment to a course of action'. Academy of Management Review, 6, 577-87.

Tjosvold, D. (1982). 'Effects of the approach to controversy on superiors' incorporation of subordinates' information in decision-making'. Fournal of Applied Psychology, 67, 189-93.

Tjosvold, D. (1985). 'Implications of controversy research for management'. Fournal of Management, 11, 21-37.

Tjosvold, D. (1998). 'The cooperative and competitive goal approach to conflict: accomplishments and challenges'. Applied Psychology: An International Review, 47, 285-313.

Tjosvold, D. and Sun, H. (2003). 'Openness among Chinese in conflict: effects of direct discussion and warmth on integrated decision making'. Fournal of Applied Social Psychology, 33, 1878-97.

Tjosvold, D. and Tjosvold, M. M. (1995). 'Cooperation theory, constructive controversy, and effectiveness: learning from crises'. In Guzzo, R. A. and Salas, E. (Eds), Team Effectiveness and Decision Making in Organizations. San Francisco, CA: Jossey-Bass, 79-112.

Triandis, H. C. (1990). 'Cross cultural studies of individualism and collectivism'. In Berman, J. J. (Ed.), Nebraska Symposium on Motivation, 37, 41-133.

Triandis, H. C., McCusker, C. and Hui, C. H. (1990). 'Multimethod probes of individualism and collectivism'. Fournal of Personality and Social Psychology, 59, 1006-20.

Tse, D. K., Francis, J. and Walls, J. (1994). 'Cultural differences in conducting intra- and intercultural negotiations: a Sino-Canadian comparison'. Journal of International Business Studies, 24, $537-55$.

Van Der Vegt, G., Emans, B. and Van De Vliert, E. (2000). 'Team members' affective responses to patterns of intragroup interdependence and job complexity'. Fournal of Management, 26, 633-55.

Van Dyck, C, Frese, M. and Sonnentag, S. (1998). 'Organizational Error Management Climate: On Enhanced Error Handling and Organizational Performance'. Paper presented at Academy of Management Conference, San Diego, CA, August.

Van Knippenberg, D., Van Knippenberg, B. and Van Dijk, E. (2000). 'Who takes the lead in risky decision making? Effects of group members' risk preference and phototypicality'. Organizational Behavior and Human Decision Processes, 83, 213-34.

VandeWalle, D., Brown, S. P., Cron, W. L. and Slocum, J. W. Jr (1999). 'The influence of goal orientation and self-regulation tactics on sales performance: a longitudinal field test'. Fournal of Applied Psychology, 84, 249-59.

Wageman, R. (1995). 'Interdependence and group effectiveness'. Administrative Science Quarterly, 40, $145-80$.

Wageman, R. and Baker, G. (1997). 'Incentives and cooperation: the joint effects of task and reward interdependence on group performance'. Fournal of Organizational Behavior, 18, 139-58.

Weldon, E. and Jehn, K. (1993). 'Work goals and work-related beliefs among managers and professionals in the United States and the People's Republic of China'. Asia Pacific Human Resource Management, 31, 57-70.

West, M. A. (1996). 'Reflexivity and work group effectiveness: a conceptual integration'. In West, M. A. (Ed.), Handbook of Work Group Psychology. Chichester: Wiley, 555-79.

Zohar, D. (2000). 'A group-level model of safety climate: testing the effect of group climate on microaccidents in manufacturing jobs'. Fournal of Applied Psychology, 85, 587-96. 